\title{
ECOLOGY
}

\section{GEO-ECOLOGICAL STUDY OF CENTRAL PIPELINE CORRIDORS IN GEORGIA}

\author{
M. Kvinikadze, D. Kuparadze, V. Kirakosyan, D. Pataridze, \\ Tbilisi State University, Caucasian Alexander Tvalchrelidze Institute of Mineral Recourses
}

DOI: https://doi.org/ 10.31435/rsglobal_ws/28022019/6347

\section{ARTICLE INFO}

Received: 11 December 2018

Accepted: 24 February 2019

Published: 28 February 2019

\section{KEYWORDS}

geo-ecology,

pipelines,

natural environment,

testing.

\begin{abstract}
At present, the main pipelines represent the most profitable economic means in terms of transportation, supply and exploitation of energy resources. Since their laying is associated with a change in the natural environment, the ecological study of these corridors is a prerequisite.

Geo-ecological study of the main pipelines is divided into three stages. This is the study of the pipeline route, to establish the existing background before the work begins. The second stage is the establishment of environmental impact during the laying of the pipeline. The third step is to monitor the environmental problems encountered during exploitation.

The presented article gives a geo-ecological study of the corridors of gas pipelines in the section 1200, 1000 and $700 \mathrm{~mm}$ on the Kazbegi-Red Bridge (North-South) section. Carried out works represents the first stage of the study, and we have identified the physical and biological characteristics of the pipeline corridors. It was determined the purity of air, noise, chemical composition of soil, water and vegetation cover, as well as engineering and geological conditions of gas pipeline corridors. The results obtained do not exceed the values of the maximum permissible concentrations adopted in Georgia and in European countries, although $\mathrm{Pl}, \mathrm{Co}, \mathrm{Ni}$ and $\mathrm{Cd}$ show increased values directly near the gas pipeline.
\end{abstract}

Citation: M. Kvinikadze, D. Kuparadze, V. Kirakosyan, D. Pataridze. (2019) Geo-Ecological Study of Central Pipeline Corridors in Georgia. World Science. 2(42), Vol.1. doi: 10.31435/rsglobal_ws/28022019/6347

Copyright: (C) 2019 M. Kvinikadze, D. Kuparadze, V. Kirakosyan, D. Pataridze. This is an openaccess article distributed under the terms of the Creative Commons Attribution License (CC BY). The use, distribution or reproduction in other forums is permitted, provided the original author(s) or licensor are credited and that the original publication in this journal is cited, in accordance with accepted academic practice. No use, distribution or reproduction is permitted which does not comply with these terms.

In the modern era it is well known that the main pipelines are necessary because they are the most economical means for the supply and operation of energy resources. As it is known, the energy supply system of Europe and Asia is based primarily on oil and gas pipelines, so they have to use new technology and then exploit their exploitation with many engineering and environmental resources. Therefore, the pipeline geo-ecology is one of the main and most important issues during such works.

In Georgia, as in other countries, the problem of pipelines is affiliated with economic and ecological issues. Through the territory of Georgia pass such main gas pipelines as: North-West Georgia (from Vladikavkaz-Tbilisi and to Yerevan); Baku-Tbilisi-Supsa; Baku-Tbilisi-Jeyhan main pipeline and Baku-Tbilisi-Erzerum municipal gas pipeline.

The pipelines listed above are independent systems with their developed infrastructure and are projected as energy source mainly for Turkey, as well as Europe. Based on the above, it is easy to understand the importance given to designing of pipelines and later, during construction and exploitation of pipelines, to consideration of environmental issues. 
The construction of pipeline itself is an essential condition for impact on the environment. Environmental work is carried out at three main stages: a description of the basic condition of the project corridor prior to work, supervision during the working period and monitoring during its operation.

The description of the baseline level of the environment defines the physical and biological characteristics of the existing environment along the proposed pipeline route prior to construction and operation. Establishment of environmental characteristics of the background means documenting the current situation, assessing the issues raised and assisting technical specialists in determining measures to minimize or eliminate negative consequences for the environment.

In the course of the work, supervision is necessary to ensure that all requirements are met to determine the environmental impact (for gas pipelines every 6 or 10 months and for oil stations after 3 and 5 months). Monitoring is also needed to assess quantitative and qualitative impact indicators. It is also worth noting that all three of these requirements are necessary for both new pipelines and also applies to their rehabilitation.

The width of the pipeline safety corridor is determined by the type of fuel and the diameter of the pipeline. If for 1200 meters of gas pipelines is required a 600 meter ecological zone (300 meters to the right of the pipe and 300 meters to the left), for oil pipelines - ecological zone of $400 \mathrm{~m}$. $(200+200$ meters) is enough. In this corridor itself several zones are allocated- 50 meters $(25+25)$ and $100(50+$ 50) meter zones. In the 50-meter zone, except for the personnel of the pipeline, human action is prohibited and in the 100-meter zone agricultural activities are allowed that are associated with the production of a one-year crop. Expansion of agricultural works is allowed only in $600(300+300)$ meter zone. The categorical restriction here concerns the existence of residential or economic facilities.

The width of the safety corridor for the oil pipeline is relatively less. Maximum is no more than 400 meters $(200+200$ meters $)$.

As noted above, the width of the pipeline safety corridor depends not only on the type of fuel but also on the pipe diameter. Vladikavkaz-Tbilisi-Yerevan main gas pipeline can be brought as an example. It enters the territory of Georgia with $1200 \mathrm{~mm}$. The width of the security corridor is 600 $(300+300)$ meter. There is a change in the diameter of this pipeline from Saguramo by $1000 \mathrm{~mm}$ and $700 \mathrm{~mm}$, which will change the width of the safety corridor. In the first case (for $1000 \mathrm{~mm}$ ) it is $250+$ $250 \mathrm{~m}$, and in the second case $200+200$ meters.

The present article contains research materials that were obtained during rehabilitation works on North-South gas pipelines. The completed works mainly cover the first stage of the study, where the geological and ecological situation in the pipeline corridor was determined. Work was carried out on a pipeline with a diameter of 1200 and $1000 \mathrm{~mm}$ and was intended for the corridor of safety and adjacent territories (see Fig.1).

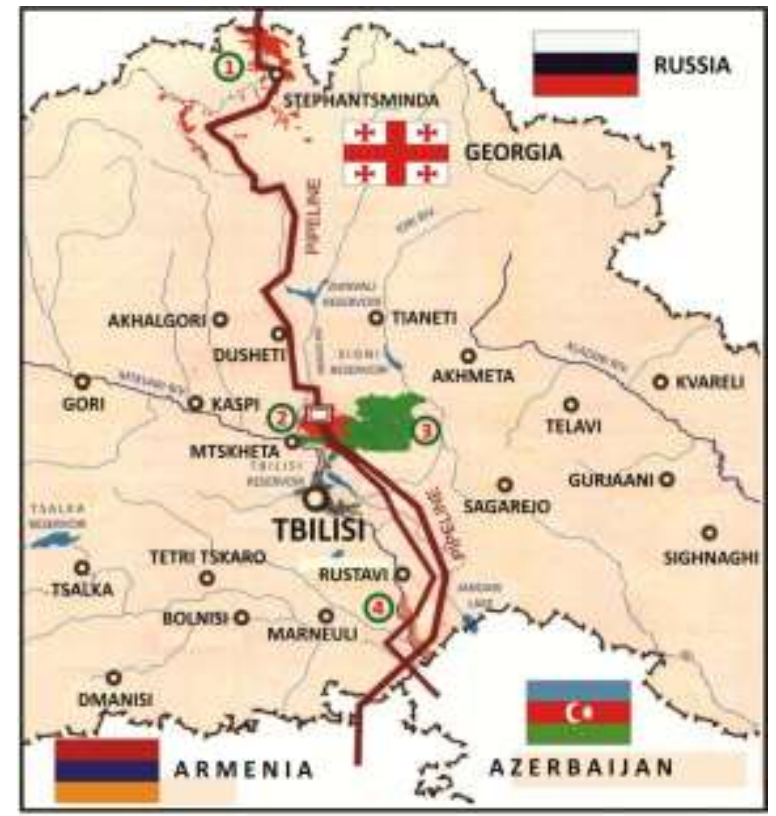

Fig.1. Kazbegi-Red Bridge gasoline schematic map

1 - Kazbegi State Reserve;2 - Saguramo State Reserve;3 - Tbilisi National Park; 4 - Gardabani reserve.

During the research, the following types of work were considered: Meteorology and climate (literary data); Determination of air quality (gas taps and gas distribution stations and adjacent territories); 
Noise determination; Geochemical study of soil; Determination of seismic safety; Hydrochemistry and hydrology; Landscapes and land use; Botanical and Zoological Studies; Sociology; Cultural heritage and description of the archaeological monuments within the pipeline and surrounding areas.

All the above-mentioned issues have been studied with regards to Baku-Tbilisi-Erzurum and Baku-Tbilisi-Supsa major routes, as well as North-South (Vladikavkaz-Tbilisi-Yerevan) gas pipeline. One of the most important factors that should be taken into consideration is that if the oil pipeline Baku-TbilisiJeyhan and Baku-Tbilisi-Erzurum are recent constructions, Baku-Tbilisi-Supsa and Vladikavkaz-TbilisiYerevan mines-tracks were undertaken for rehabilitation works, engineering and ecological researches.

Given the geographical situation, the territory of Georgia is known as territory with soft and mild climate conditions. The Caucasus Mountains protect it from the North -from the cold air mass invasion from the lowlands of Russia, therefore, the whole territory of Georgia is maintained by high heat regimes, thus sharp meteorological changes rarely occur.

The entire territory of Georgia is divided into two climatic zones. This is the West -humid subtropical climate zone, which has great influence on the Black Seaand the East - dry subtropical climate zone, which is located under the hot air mass coming from the South. The divider of those climate zones is Surami ridge. As for the extreme South-East part, it is represented by a semi-desert subzone.

Meteorological data defines wind direction, its speed, duration of sunlight, air temperature change and precipitation rates. All these data is taken from multiple yearly observations of relevant stations and represent average annual indicators.

Air quality determination is one of the essential criteria among ecological indicators, especially for gas pipelines. The air quality assessment is based on the area of gas distribution stations and the surrounding territories to reduce the amount of gas leakage (which is not rare at gas distribution stations) and avoid ecological damage to the area where this station is located. Similar to meteorological data, the data of air quality was taken from data base created in the 80s of the last century.

With regards to the impact on the environment, the following facilities were named as the main cause of the ecological deterioration: energy production, transport, industry process, forestry ecosystems and village farm.

As it is clear from the listas well, the energy production isone of the main sources of air wounding. The good example is the gas pipeline - Vladikavkaz-Tbilisi-Yerevan. Surveys conducted during the construction of the pipeline to assess the air qualityhave revealed that the main loadis relatedto stations, therefore, the quality of the air depends on the intensity and operation of the stations.

As the example can be cited the fact that during the construction works, gas leak was observed at two gas pump stations. In addition, in two places due to the damage of the gas pipe line, gas leak was very intensive, which caused air pollution over long distance.

During the ecological studies besides air quality, it is necessary to define noise level as it is a direct source of negative impact on the population.

The noise level determination was implemented on Vladikavkaz-Tbilisi-Yerevan trails. The analysis indicated that the noise tones on the pipeline safety corridor are low and do not exceed Georgia's standard stable units. The reason for this is that almost 90-95\% of the pipeline passes through agricultural or pasture areas and has no or minimal contact with motorways, cities and populated areas. As for the noise tunes generated by the heavy equipment during works, it arises in a short period of time and is easy to control because, as mentioned above, the pipeline and pipeline routes are far from populated areas.

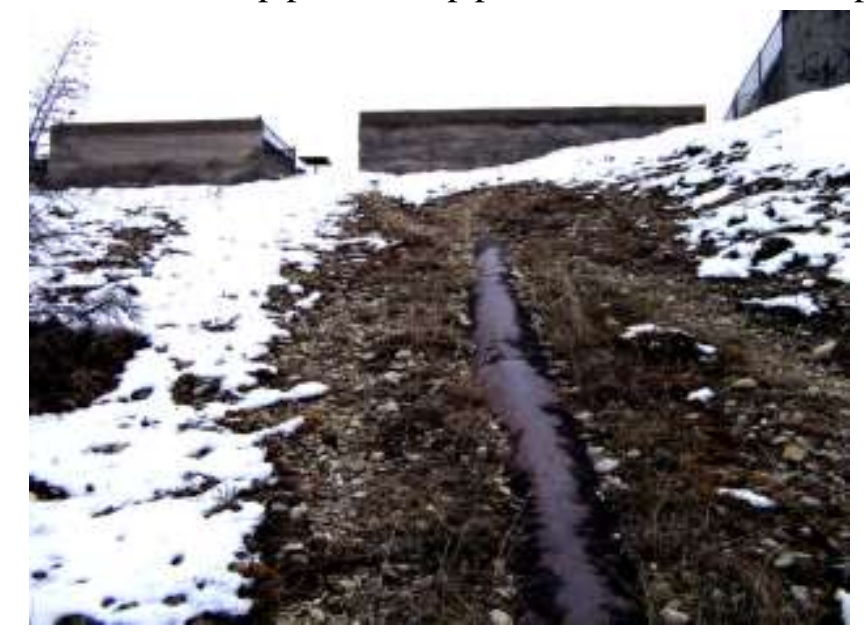

Fig.2. Pipeline landscape 
Ecological studies have also evaluated such issues as the geomorphologic structure along the trajectory, hydro geological chassis, the determination of geological hazard risk factors and the seismic hazard.

The geomorphology briefly describes the peculiarities of landscapes in the pipeline corridor. Based on the materials obtained during the field works all geomorphologic classes existing in the corridor were singled out and described.

During geologic studies, lithological types of all rocks, their structural and tectonic peculiarities have been studied.

In the hydrogeology, the precipitated horizons, water hydrological hosiery and chemical composition of water were singled out and presented on the basis of data from previous researchers.

Erosion classes have been established and evaluated by their proposals. For example, the issue was raised to move pipes from two sections of the Vladikavkaz-Tbilisi-Yerevan pipeline (Fig.2).

Special study has been undertaken in the pipeline corridor on soil and water resources (river, tributary, source, water reservoir, etc.) used by the gas pipeline.

Due to the scale of works, soil and water samples have been taken along the entire route (from all varieties). Laboratory research has revealedheavy and toxic metals, organic substances and all chemical elements that have beenintroduced into soils and waters during construction works in previous years.

The results obtained by us (our results) have been compared to the Holland standards adopted in Europe, as well as the World Standards (see Table 1).

Table 1. Consistency of chemical elements in soils, gasoline Kazbegi-Red Bridge section

\begin{tabular}{|c|c|c|c|c|c|c|c|c|c|}
\hline \multirow{2}{*}{$\begin{array}{l}\text { Ser. } \\
\text { №№ }\end{array}$} & \multirow[t]{2}{*}{ Coordinates } & \multirow{2}{*}{$\begin{array}{c}\text { Sample } \\
\text { №№ }\end{array}$} & \multicolumn{7}{|c|}{ Consistency of chemical elements in soils, $\mathrm{mg} / \mathrm{kg}$} \\
\hline & & & $\mathrm{Cu}$ & $\mathrm{Pb}$ & $\mathrm{Zn}$ & Co & $\mathrm{Ni}$ & $\mathrm{Cd}$ & As \\
\hline 1 & 2 & 3 & 4 & 5 & 6 & 7 & 8 & 9 & 10 \\
\hline 1 & $\begin{array}{l}8482088 \\
4634447\end{array}$ & 6 & 36.7 & 115.9 & 26.3 & 31.6 & 84.3 & 3.2 & 0.21 \\
\hline 2 & $\begin{array}{l}8480440 \\
4634847\end{array}$ & 7 & 51.5 & 92.7 & 25.7 & 30.9 & 92.6 & 3.1 & trace \\
\hline 3 & $\begin{array}{l}8474503 \\
4635328\end{array}$ & 8 & 47.5 & 94.3 & 31.6 & 31.6 & 94.9 & 2.6 & 0.13 \\
\hline 4 & $\begin{array}{l}8485379 \\
4633287\end{array}$ & 9 & 41.2 & 82.4 & 25.8 & 28.4 & 82.5 & 2.6 & 0.16 \\
\hline 5 & $\begin{array}{l}8491936 \\
4631636 \\
\end{array}$ & 10 & 42.7 & 96.1 & 26.7 & 32.1 & 117.5 & 3.2 & 0.13 \\
\hline 6 & $\begin{array}{l}8497439 \\
4626200 \\
\end{array}$ & 11 & 47.6 & 95.1 & 18.5 & 29.1 & 126.7 & 3.2 & trace \\
\hline 7 & $\begin{array}{l}8498516 \\
4625501 \\
\end{array}$ & 12 & 42.2 & 95.0 & 34.8 & 29.0 & 73.9 & 3.7 & 0.23 \\
\hline 8 & $\begin{array}{l}8499156 \\
4625231\end{array}$ & 13 & 36.7 & 73.4 & 31.5 & 31.5 & 115.4 & 3.6 & 0.10 \\
\hline 9 & $\begin{array}{l}8505983 \\
4611431 \\
\end{array}$ & 14 & 52.5 & 94.4 & 31.5 & 31.4 & 121.7 & 3.6 & trace \\
\hline 10 & $\begin{array}{l}8507655 \\
4608072 \\
\end{array}$ & 15 & 47.7 & 95.5 & 37.2 & 39.8 & 95.5 & 3.8 & 0.19 \\
\hline 11 & $\begin{array}{l}8508185 \\
4607008 \\
\end{array}$ & 16 & 22.4 & 55.8 & 25.2 & 25.2 & 134.2 & 3.7 & 0.10 \\
\hline 12 & $\begin{array}{l}8503853 \\
4615086 \\
\end{array}$ & 17 & 38.3 & 87.6 & 32.8 & 32.8 & 120.5 & 3.3 & trace \\
\hline 13 & $\begin{array}{l}8504324 \\
4614248\end{array}$ & 18 & 59.9 & 98.0 & 32.7 & 32.6 & 119.8 & 2.7 & trace \\
\hline 14 & $\begin{array}{l}8505033 \\
4613453 \\
\end{array}$ & 19 & 61.3 & 100.3 & 33.4 & 33.4 & 122.8 & 3.3 & 0.41 \\
\hline 15 & $\begin{array}{l}8509769 \\
4604016 \\
\end{array}$ & 20 & 16.9 & 71.7 & 21.1 & 29.0 & 94.9 & 4.5 & trace \\
\hline 16 & $\begin{array}{l}8510141 \\
4603131 \\
\end{array}$ & 21 & 31.6 & 94.8 & 15.8 & 31.6 & 115.9 & 2.6 & 0.23 \\
\hline
\end{tabular}


Continuation of table 1 .

\begin{tabular}{|c|c|c|c|c|c|c|c|c|c|}
\hline 1 & 2 & 3 & 4 & 5 & 6 & 7 & 8 & 9 & 10 \\
\hline 17 & $\begin{array}{l}8512338 \\
4593941\end{array}$ & 22 & 39.7 & 114.8 & 26.1 & 36.5 & 83.5 & 3.6 & 0.13 \\
\hline 18 & $\begin{array}{l}8511598 \\
4593049\end{array}$ & 23 & 47.9 & 117.0 & 37.2 & 39.9 & 106.4 & 3.7 & trace \\
\hline 19 & $\begin{array}{l}8510975 \\
4592310\end{array}$ & 24 & 29.5 & 73.6 & 21.0 & 36.8 & 94.6 & 2.6 & trace \\
\hline 20 & $\begin{array}{l}8509260 \\
4590191\end{array}$ & 25 & 49.2 & 609.6 & 32.1 & 37.4 & 117.6 & 3.2 & trace \\
\hline 21 & $\begin{array}{l}8509547 \\
4589812\end{array}$ & 26 & 40.6 & 106.9 & 32.0 & 37.5 & 96.2 & 3.7 & 0.19 \\
\hline 22 & $\begin{array}{l}8510567 \\
4586775\end{array}$ & 27 & 29.1 & 582.1 & 20.7 & 31.2 & 93.5 & 2.6 & 0.18 \\
\hline 23 & $\begin{array}{l}8509872 \\
4585919\end{array}$ & 28 & 52.9 & 148.1 & 44.9 & 37.0 & 105.8 & 3.7 & 0.29 \\
\hline 24 & $\begin{array}{l}8505895 \\
4580580\end{array}$ & 29 & 36.0 & 113.3 & 30.9 & 36.0 & 92.7 & 3.6 & 0.10 \\
\hline 25 & $\begin{array}{l}8505895 \\
4580580\end{array}$ & 30 & 24,5 & 71.6 & 25.6 & 30.7 & 92.0 & 3.1 & 0.12 \\
\hline 26 & $\begin{array}{l}8505895 \\
4580580\end{array}$ & 31 & 37.3 & 77.8 & 25.9 & 31.1 & 83.0 & 3.1 & 0.28 \\
\hline 27 & $\begin{array}{l}8506029 \\
4559158\end{array}$ & 32 & 37.5 & 583.9 & 26.1 & 31.3 & 72.9 & 3.6 & 0.13 \\
\hline 28 & $\begin{array}{l}8502449 \\
4579828\end{array}$ & 33 & 46.3 & 771.6 & 30.9 & 30.9 & 72.0 & 2.6 & trace \\
\hline 29 & $\begin{array}{l}8502608 \\
4580503\end{array}$ & 34 & 36.7 & 550.9 & 31.5 & 28.8 & 83.9 & 3.1 & not \\
\hline 30 & $\begin{array}{l}8506273 \\
4578810\end{array}$ & 35 & 38.1 & 94.5 & 26.3 & 31.5 & 73.5 & 3.1 & not \\
\hline allowable & & 36 & 85 & 140 & 20 & 35 & 0.8 & detected \\
\hline
\end{tabular}

As clear from the table, there are exceptional high content emitters $\mathrm{Co}$, Ni and $\mathrm{Cd}$. Their indicators were observed near the gas pipeline, almost along the entire route. In the soil samples taken 200 meters away from the pipeline the content did not exceed the standards. There is also higher content of $\mathrm{Pl}$ in some samples which can be explained by the pollution left by heavy equipment during the construction work. As for the water samples, they fully satisfy given standards.

In conclusion we can say that all necessary researches on the ecological condition of the corridor along the pipeline envisaged by the first stage have been carried out. As for the second and third stages, their implementation is planned in the coming years, after rehabilitation and exploitation works within the pipeline are completed.

\section{REFERENCES}

1. Y.L. Maksimenko, V.A. Glukharev. Environmental norms and projection regulations. //Magisterial pipelines (pages 455-470). Moscow, publishing house Stroiizdat, 1990, page 523 